\section{Simultaneous Pulmonary Arterial and Venous Round Structures in Pulmonary Aspergillosis}

Shusuke Yagi, MD, PhD;

Hiromu Yamazaki, MD, PhD;

Susumu Nishio, PhD;

Kenya Kusunose, MD, PhD;

Hirotsugu Yamada, MD, PhD;

Masataka Sata, MD, PhD

A 65-year-old man was admitted with worsening dyspnea due to interstitial pneumonia. He had been previously diagnosed with rheumatoid arthritis and had had pulmonary atypical mycobacteriosis and aspergillosis for 2 years. He had no history of arrhythmia. The rheumatoid arthritis was treated with prednisolone and methotrexate; pulmonary atypical mycobacteriosis with ethambutol, clarithromycin, and sitafloxacin; and pulmonary aspergillosis with voriconazole. Compared with previous imaging (Figure A), plain computed tomography (CT) showed progressive lung destruction, especially in the left upper lobe (Figure B); enhanced CT showed round structures in the left pulmonary artery (Figure C,D, blue arrows) and in the left upper pulmonary vein (Figure C,D, red arrows), without deep vein thrombosis. On echocardiography these were seen to be mobile thrombi or fungus balls (Movie S1). Lung ventilation and perfusion scintigraphy both showed a defect in the left upper lobe due to lung destruction. The laboratory data did not meet the criteria for disseminated intravascular coagulation (Appendix S1). The patient was given anti-coagulation therapy involving heparin and warfarin, and antibiotics consisting of tazobactam/piperacillin for pneumonia, but the therapy did not result in any change in the size of the structures, and he died from pneumonia exacerbation 12 days after admission.

Herein, we report the first case of non-surgical round structures presumed to be thrombosis in the pulmonary artery and vein. Histology could not be carried out, however, because autopsy was not performed. Progressive destruction of the left lung, due to disturbed pulmonary blood flow and chronic inflammation from aspergillosis, might cause simultaneous pulmonary arterial and venous thrombosis.

\section{Acknowledgments}

None.

\section{Disclosures}

The authors declare no conflicts of interest.

\section{Supplementary Files}

Supplementary File 1

Movie S1. Echocardiographic imaging of mobile structures.

Supplementary File 2

Appendix S1. Laboratory Data

Please find supplementary file(s);

http://dx.doi.org/10.1253/circj.CJ-18-0898

Received August 8, 2018; revised manuscript received September 20, 2018; accepted October 9, 2018; J-STAGE Advance Publication released online November 3, 2018 Time for primary review: 30 days

Department of Cardiovascular Medicine (S.Y., H. Yamazaki, K.K., H. Yamada, M.S.), Department of Community Medicine and Human Resource Development (S.Y.), Tokushima University Graduate School of Biomedical Sciences, Tokushima; Ultrasound Examination Center, Tokushima University Hospital, Tokushima (S.N.), Japan

Mailing address: Shusuke Yagi, MD, PhD, Department of Cardiovascular Medicine, Tokushima University Graduate School of Biomedical Sciences, 3-18-15 Kuramoto-cho, Tokushima 770-8503, Japan. E-mail: syagi@tokushima-u.ac.jp

ISSN-1346-9843 All rights are reserved to the Japanese Circulation Society. For permissions, please e-mail: cj@j-circ.or.jp

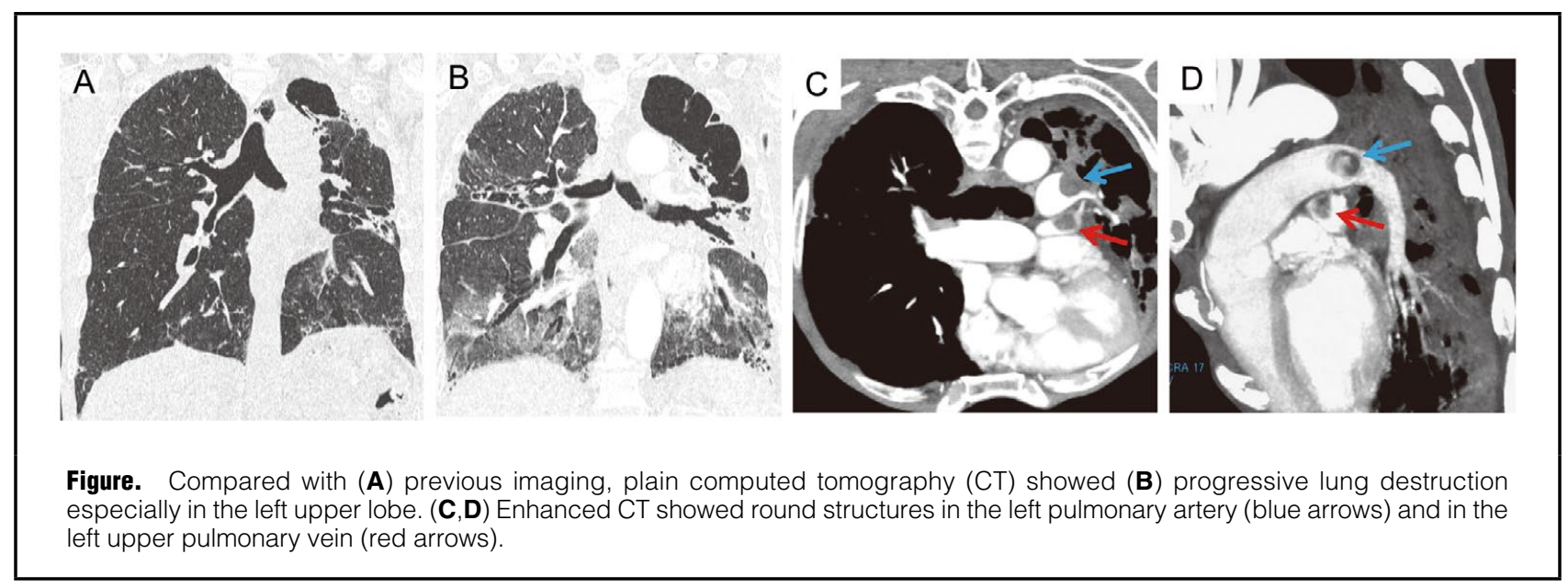

